\title{
Characterising work-based learning as a triadic learning endeavour
}

Chris Kemp, Patrick Smith, Roger Dalrymple

Corresponding author:

Dr Roger Dalrymple

Faculty of Health and Life Sciences

Oxford Brookes University

Jack Straw's Lane

Marston

Oxford

OX3 OFL

rdalrymple@brookes.ac.uk 


\title{
Characterising work-based learning as a triadic learning endeavour
}

\author{
Chris Kemp ${ }^{a}$, Patrick Smith ${ }^{a}$ and Roger Dalrymple ${ }^{* b}$ \\ ${ }^{a}$ Buckinghamshire New University, Buckinghamshire, United Kingdom; ${ }^{b}$ Oxford Brookes University, \\ Oxford, United Kingdom.
}

\begin{abstract}
With work-based learning (WBL) forming an increasingly prevalent dimension of modern higher education practice, conceptual models of the pedagogies underpinning WBL are increasingly emerging. Recognition is broadening that there is a need to capture and represent the values and presuppositions underlying WBL in order to support facilitators and learners engaged in WBL for the first time. Accordingly, the current study proposes a new characterisation of WB higher education which can helpfully inform the design and delivery of WBL curricula, schemes of work, and teaching and learning strategies. Informed by the authors' extensive facilitation of WBL programmes for such diverse fields of professional practice as dance-teaching, event management, security and the military, the model represents WBL as a triadic learning endeavour in which student, work-based facilitator and university tutor are engaged in a mode of learning which is best conceived as 'academy-aligned' rather than 'academy-based' and in which the signature pedagogic principle is one of 'responsive facilitation'. The application of the model in a number of programmes is demonstrated and some recommendations for WB practice outlined.
\end{abstract}

\section{Principles of work-based learning}

Work-based learning (WBL) has become an increasingly salient feature of the higher education landscape in recent years. As work-based awards have broached new curricular areas and learning contexts, the frameworks of quality assurance have sought to keep pace (QAA Code of Practice, 2007; QAA Scotland Guide to WorkBased Learning, 2010) while theoretical studies have also sought to specify how WBL pedagogies are distinct from other higher education practices. Foundational work by Marsick, (1987) and Marsick \& Watkins, (1990) on workplace learning has more recently been supplemented by Eraut (2000 \& 2009), Boud and Solomon (2001), Jarvis (2001), and Raelin (2008), and a number of UK universities have established work-based learning institutes and centres to extend the scholarly base for WBL in higher education. 
Much of the extant literature on WBL rightly emphasises the role played by reflection in recognising and evaluating learning experiences and opportunities as they occur, upon subsequent consideration, or in anticipation of future events (Schon,1983 \& 1987; Cowan, 1998). Acknowledging this central role of reflection, Raelin (2008) identifies three critical and distinctive elements in the WBL process; firstly that learning occurs in the midst of action, secondly that knowledge-creation and utilisation is a collective and social process, and finally that a positive disposition in work-based learners towards 'learning to learn' is essential. These principles established, Raelin calls for the development of a work-based pedagogy, one which is inclusive and acknowledges the ubiquity of learning opportunities and contexts:

[I]f knowledge is viewed as arising as much from active participation in the very apparatus of our everyday life and work, then we have to expand our conventional format of the classroom and indeed, interpret the home and the workplace as suitable loci for learning.

(Raelin, 2008: 64)

For facilitators of WBL, the implications of such a stance are dramatic and profound, posing a formidable challenge to conventional academic practices, roles and identities. ${ }^{1}$ Indeed, the authors' experience of WBL facilitation suggests that a blurring of contexts, identities and roles is at the very heart of realising Raelin's three elements. Whereas the majority of the WBL literature rightly focuses attention on those structures required to create effective links between the workplace and the institution (Nixon et al, 2006; COBE, 2006), our own emphasis in this article is on the pedagogic regime in action, that is, how learning and reflection are encouraged and facilitated both in the workplace and in more formal learning environments.

\footnotetext{
${ }^{1}$ Throughout the article we use 'Facilitator' to denote a higher education lecturer engaged in work-based learning; 'Industry Specialist' to indicate a work-based co-facilitator of a programme; and 'Participant' to indicate a learner enrolled on a work-based learning programme.
} 


\section{Outcomes of work-based learning}

We suggest that the more interactive and stimulating the pedagogic conditions, that

is, the more realistic and relevant to participants the learning milieu is, the more the consequent outcomes will be complex, generative and yet unpredictable. They are complex insofar that what counts as 'knowledge' is drawn from a range of sources and tends to be both provisional and trans-disciplinary in nature (Raelin, 2008): surfacing tacit and long-held conceptions of knowledge requires both time and conditions of trust in order to negotiate collective understandings of the nature of theory and how it relates to diverse working contexts. The outcomes are generative in that the extent of enquiry and discussion can often range well beyond the defined academic level of the programmes involved as work-based participants explore ideas and approaches in relation to their own workplaces. Finally, the entire process tends to become unpredictable as participants realise and understand the links between their tacit and 'gut' understandings, the understandings of their peers and how these are manifested in, and related to, their workplaces - a situation which can be captured in two core principles as follows:

- Work-based learners will more readily take the risk of questioning their knowledge and practice when they have freedom of informed choice, a degree of control of the learning process, responsibility for the learning outcomes and both the security and the challenges of a group of peers. (Crawshaw, 2008; Revans,1998; Rogers, 1986).

- Work-based learners will prove more effective when they regard themselves as active agents responsible for their learning, and when they view mistakes and errors as the raw material for learning rather than sources of embarrassment. (Marsick and Watkins, 1990).

This condition of unpredictability has significant ramifications not only for what occurs in workplaces and seminar rooms, but also in terms of quality assurance mechanisms and procedures. It might not be too dramatic to claim that it represents 
a paradigm shift in terms of learning, and one of the most challenging aspects of higher learning 'outside the academy'. It is about customising and personalising the curriculum to circumstances, individuals and groups -

And doing that, I think, is the answer to the future because it's not about scaling a new solution, it's about creating a movement in education in which people develop their own solutions, but with external support based on a personalised curriculum.

(Robinson, 2010)

The implications of what Robinson outlines here are extensive and exciting for facilitators of WBL, albeit problematic in terms of potential outcomes. The authors' experience suggests that WBL programmes increasingly share these aspirations in as much as they are seek to develop a positive and productive pedagogic context in which meaning and learning are co-constructed and shared.

\section{The need for WBL pedagogies}

With the increasing prevalence of WBL programmes in higher education there is a demonstrable need to evolve new pedagogic models to support facilitators and participants in conceptualising and developing practice. The need is the more acute given that designers and facilitators of WBL programmes are confronted by two central challenges which distinguish WBL from academy-based higher education provision. First, they are increasingly obliged to bring together different academic disciplines in order to serve the emerging needs of industries and to develop interdisciplinary approaches which are in line with governmental insistence on employability as a core driver of the educational agenda. Secondly, they are obliged to take into fullest possible account the needs of learners - mature, experienced adults who in some instances may have few formal qualifications, but who will possess considerable existing knowledge pertaining to their field of professional 
practice, and understandable anxiety and even scepticism about involvement with academia.

The relatively slow emergence of practice-facing models of WBL pedagogy may relate to wider perceptions and assumptions concerning the nature and status of work-based higher education. While the workplace has been acknowledged as an key element in the socialisation of individuals, the best that is often claimed for it as a source of learning and development is that it serves as a venue for 'informal and incidental learning' (Marsick \& Watkins, 1990). Yet in dialogue with the authors' experience of work-based facilitation, and with the growing WBL literature, we propose below a model that makes more substantive claims for the value and place of WBL. The model is indebted to existing paradigms (Boud and Solomon: 2000) but gives fuller than customary regard to the interdependent roles of university tutor, work-based facilitator and learner in the WBL process. The model characterises the WBL endeavour as triadic (we purposefully adopt a term from music theory with the associated connotations of harmony rather than the more mechanistic term 'tripartite'), and views WBL activities as 'academy-aligned' rather than 'academybased' (a distinction that seeks to explain the more contested status in some quarters of WBL as a legitimate higher education activity). The model proposes that in effective WBL programmes, this interdependence is acknowledged across the full range of pedagogic activity, from curriculum design to programme delivery and assessment. 


\section{Work-based Learning: a triadic learning endeavour}

A common conception of work-based learning implies a dialogic approach to student learning, where an industry specialist privileging practical knowledge, and a university facilitator privileging theoretical knowledge create a synthesis for the learner to access and reflect upon. Yet the process of WBL is arguably better conceived as triadic, with the learner's role being considerably more proactive and with no meaningful synthesis of the practical and the theoretical being achieved until the contributions of the three parties to the triad are fully harmonised. We suggest the most effective configurations of WBL involve the confluence of university facilitator, industry specialist, and participant (perhaps better described in this context as 'learning practitioner') who together establish a learning context in which theory, practice and disciplinary knowledge cohere. Without this alignment of three distinct agents in the learning process, the gap between theory and practice can become exaggerated and negotiations between 'academy-based' theorist and 'industry-based' practitioner accordingly vexed. Moreover, any notion of the university facilitator as custodian of academy-based knowledge we hold to be of limited value in a WBL context: for despite a rich tradition in educational development of working across disciplines and academic boundaries, a university lecturer inputting into WBL programmes can hardly hope to gain mastery of each of the fields of professional practice for which s/he is providing WBL facilitation. The academic's contribution to the process is instead centred upon introducing and exploring more generic concepts in experiential learning and development, leaving the role of discipline specialist to a second party to the triad - the industry-based specialist with subject-specific credentials in the eyes of the participants. The university facilitator works not dialogically, as an academy-based university lecturer 
might be seen to do, but as an equal member of the triad, all of whose members are central to the realisation of learning. We suggest that it is by means of this triadic learning endeavour that WBL is best facilitated. The triad enables university facilitators and industry specialists to tap into the reservoir of learners' prior experience and expertise in order both to motivate them and to 'earth' new concepts, ideas and approaches into the learners' reality (Knowles, 1978; Mezirow, 2000; Jarvis, 2001; Jarvis et al, 2003, \& Raelin, 2008)). The triad promotes the engagement of learners and encourages application of theoretical propositions to their own working lives.

There are significant advantages to this type of learning. First, it better reflects that ‘unruly domain of professional practice and trans-disciplinary knowledge' (Boud \& Solomon, 2000:2) with which work-based learners are familiar and to which they can relate. It has relevance not only to their work style and activity, but also to the interdisciplinary nature of the often informal learning which characterises the workplace. Secondly, this familiarity reduces the perception of an 'us and them' situation by rooting the curriculum in realistic terms. Thirdly this type of approach promotes group cohesion, through sharing, problem-solving and, encountering different opinions and perceptions. The process of negotiating understandings and approaches within task-based groups draws on often familiar skills and promotes peer learning. Indeed, it also raises the major question, 'In this situation, who exactly is the learner?' 


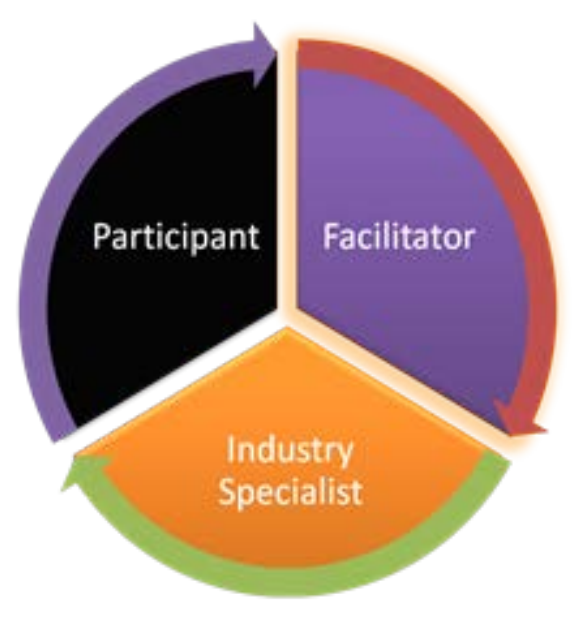

Figure One. Work-based learning: a triadic learning endeavour

The identities of the three parties engaged in this triadic process are not as fixed as in a traditional university setting but are more fluid in realisation and operation. One of the consequences of this fluidity is the emergence of different roles and identities for those concerned in the process, participants, industry specialists and university tutors. The conditions are created in which learners become co-producers of knowledge and understanding through utilisation of their experience and practice examples as curricular content. Such a process can prove highly rewarding and motivating. Certainly, in the authors' experience of WBL facilitation, at the level of the individual participant, a genuine thirst for knowledge is often catalysed. Having committed to entering the programme, learners frequently discover a zest for knowledge beyond that which represented by the ostensible reason for their initial involvement. Often they are genuinely surprised and even shocked by the intensity with which they apprehend and explore ideas and relate them to their professional practice, and by the outcomes engendered by some of the learning episodes and exchanges in which they take part. 
Moreover, just as each contributor to the triad brings with them specialist knowledge and expertise, so each brings areas of ignorance and lack of experience: indeed, acknowledgement of a degree of vulnerability is an essential prerequisite to the construction of knowledge in this context. Schraam's model of communication (Mortensen 1972) and messaging systems demonstrates how encoded and decoded messaging elements are understood (or not) by parties from different discourse communities. Facilitators from industry backgrounds who have subsequently assumed academic roles are often well placed to deliver and contextualise such activities since their career biographies effectively enact the fusion of practice and theory that work-based learning programmes seek to realise. The result is a special learning relationship brought about by the creation of a common purpose in which a community of practice emerges through knowledgesharing, exploration and transfer in the light of individual and professional needs

The process of establishing this sort of climate of relations within a group calls for facilitators to possess a broad repertoire of so-called 'soft' skills. Indeed, on occasion, it can call for a degree of subterfuge as the facilitator creates that scaffolding that enables and encourages learners to take the first tentative steps into the unknown, or the dimly perceived, in short into their 'Zone of Proximal Development' (Vygotsky 1978). Having once extended learners' understandings and afforded the opportunities for them to integrate what has been experienced and understood with what was previously known, either individually or in groups, facilitators can then move the learning on in the knowledge that participants themselves will be willing partners in the process. 


\section{Work-based learning as academy aligned practice}

This notion of WBL as a triadic learning endeavour represents a sufficient departure from established models of higher education pedagogy that we suggest university facilitators of WBL programmes do well to conceptualise their practice as no longer academy-based but as academy-aligned. In Raelin's words, 'The classroom need no longer be the sanctuary for learning' (2008: 16). One of the principal challenges for the academy-aligned facilitator in such a situation is less to introduce new propositional and procedural knowledge to learners (as an academy-based colleague might) but instead to work with practitioners to surface and make explicit that which, through repeated exercise, has become tacit. This process resonates with Lunderberg's (1987) observation that 'experts who engage in a process automatically probably do not know how they know what they know' (Lundeberg, 1987: 409) and bears out the observation that experienced practitioners are often unable to articulate those processes that they engage in habitually (and often unconsciously). This situation, termed 'tacit understanding' by Polanyi (1973), is not uncommon as practitioners develop their knowledge and skill bases through daily use. Eraut's work (1994 \& 2009) illuminates these difficulties and he cites the Dreyfus model of progression in relation to learning in the workplace. The individual moves from Novice - a stage characterised by adherence to rules and procedures with little situational awareness and no discretionary judgement, to Expert - the stage at which rules are transcended and situations analysed by means of an intuitive grasp of meanings and features. Accordingly, while many participants on WBL programmes are experts in their own fields, their awareness of how they operate can remain deeply buried. The facilitator's role, in part, is to help create awareness of those habitual and unconscious behaviours that participants rely upon, 
in order to encourage them to re-evaluate their responses and develop fresh understandings.

It is clear that this type of learning activity calls for an extensive repertoire of techniques on the part of the facilitator, whereby the discriminate exercise of approaches from this repertoire are selected and used to enable participants to apprehend a concept and grasp its significance in the light of their own agendas and needs - in short to construct their understandings in unique and original ways. We agree with Jaques (2000) and Van der Elst (2009) on the value of active, experiential methods, such as case studies, scenarios, table-top exercises used in conjunction with action research and learning, in obliging learners to engage in determining what is learned.

\section{The pedagogy of work-based learning as 'responsive facilitation'}

The practice of work-based learning thus calls for responsive facilitation on the part of the university tutor. In encouraging participants to identify and critically evaluate their understandings and practices, facilitators must beware treating the associated skills as detached and separate from the individual participant's life and work (Gamache, 2002). The responsive facilitator must establish a positive learning environment and create a culture of support, acknowledging and responding to the need for learner autonomy and creating those conditions which enable participants to learn at a speed which is comfortable for them. In the authors' own facilitation of WBL programmes, an academic skills module invariably operates alongside the main curriculum in order to respond to participants' diverse needs and to help develop and consolidate specific skills as and when participants need them. The 
facilitator should also be sufficiently conversant with notions of curriculum alignment (Biggs and Tang, 2011) to ensure that an integrated learning and assessment regime underpins the knowledge base of each participant.

The role of the responsive facilitator is complex and multifaceted. Those undertaking such a role must be credible and secure in their knowledge and understanding of both the facilitation and learning process and the world from which individual participants have come into education. Their enthusiasm and thirst for knowledge has to match that of the participant as the process is reciprocal with each of the actors in the triad - participant, industry-specialist and facilitator learning from the process in which they are mutually engaged.

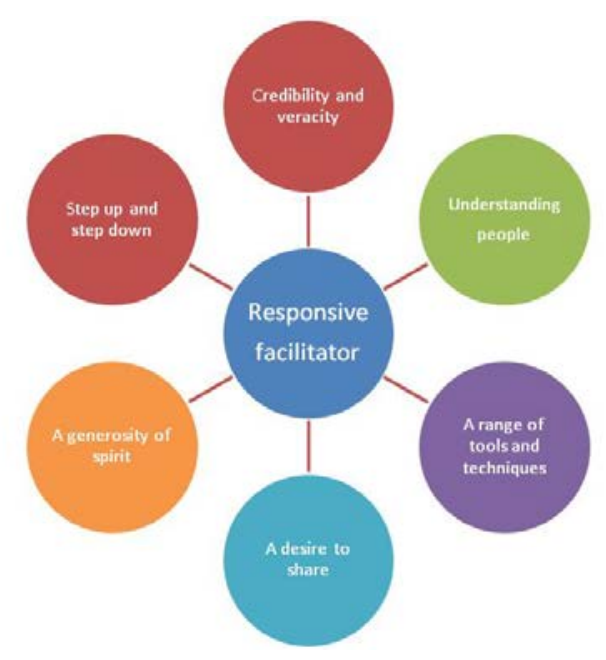

Figure Two. The Role of the Responsive Facilitator.

For the facilitator then, the role is particularly demanding, involving knowledge and expertise in relation to a range of theoretical fields, including curriculum design, implementation and those inter-personal skills which make for effective learning. More significant perhaps is the desire to share knowledge and to encourage 
the participant to develop an appreciation and understanding of how they learn, in short to develop the skills of self-directed learning and metacognition. Allied to this is what might best be termed a generosity of spirit, a predisposition not only to facilitate the learning of participants, but to acknowledge those lacunae in their own understandings and the ability to learn oneself from the experiences and expertise of the participants in order to ensure that effective learning occurs.

Finally the facilitator must be adept at both 'stepping up' and 'stepping down' when the participants are either struggling to grasp an area or when their knowledge is such that they stray well beyond what is expected at a particular level. It is not unusual for the facilitator to find that, given the experience and interests resident within groups, the exploration of concepts and practices moves well beyond the requirements of a particular module. At such times perhaps the most influential element will be the facilitator's particular 'corridor of tolerance' (McAlpine et al, 1999) - that is, the extent to which s/he curtails or encourages an apparently tangential line of enquiry.

All of these factors make for a different conception of the facilitative role. Academyaligned facilitation involves ongoing dialogue and feedback with the other members of the triadic learning endeavour: it requires 'extended and negotiated facilitation' since it is in the workplace that multi/uni or trans-disciplinary practice is taking place, either at set times or incidentally as part of working practice. This practice represents the principal focus of learning - in Boud \& Solomon's (2000) terms, the workplace becomes the curriculum which is explored and analysed by means of active 
experiential methods. In such cases, the learning venue is not only multifunctional, but ubiquitous: potentially everywhere is the learning place or space (Boud \& Solomon 2000; Eraut 2009).

In WBL, the learning place or space is expanded to accommodate different types of learning in different venues. The use of flexible and distributed learning enables interfaces between participants, facilitators and industry specialists to take place in a number of permutations, all of them in the workplace, all of them in the university space and all of them in intentionally contextualised settings. Inevitably such an approach has significant epistemological implications, not the least of these being that content knowledge is drawn from a range of disciplines - a situation which reflects the diversity of those working contexts in which the participants operate, where knowledge is merged and dissolved to focus on specific problems and their resolution. The resulting situation is one in which there is a continual forming, reforming and dissolving of fields of knowledge; content, concepts, and interfaces are rapidly created, utilised and refocused. In Huff's (1999) terms, WBL practitioners are concerned with 'Mode Two knowledge' which derives not from the declarative knowledge of the traditional university, but rather that resulting from practical application and thus procedural knowledge. The fluidity and transience of the knowledge base requires flexibility, innovativeness and deftness - qualities which are indeed considered the prerequisites of higher educational thinking, be it within or outside the academy. 


\section{Challenges in the triadic relationship: some examples from practice}

Throughout this article we have referred to the realisation and operation of the triadic relationship as challenging, complex and problematic, requiring flexibility, dexterity and a tolerance of uncertainty and ambiguity. Each party to the triad experiences challenges which are both generic and specific to their particular role and context. In this closing section we briefly outline some examples of these challenges with reference to the WBL programmes in which the authors have been involved in recent years, each accredited by a post-1992 HEI based in the south-east of England. The programmes include Bridging the Gap (a short HE level course for further education lecturers); a Certificate in Work-based Learning (delivered for a range of professionals including those in uniformed services), along with a range of Foundation Degree programmes in education and health and social care.

\section{Bridging the Gap}

This was a short course comprising three, two-day intensive workshops, introducing further education lecturers to aspects of event management in order for them then to run Level Two stewarding programmes. The principal challenges were as follows.

- Differentiation: some participants had extensive knowledge of the event management industry, whilst others had been volunteered by the colleges having no experience of the industry

- Entry level: briefing of the participants by their colleges ranged from the comprehensive to the non-existent - one participant had been instructed to attend the programme only the day before the inaugural session. 
- Learning environment: the programme operated in a range of settings conference centres, the accrediting university, contributing colleges - and the respective participants had to make adapt rapidly to circumstances and facilities.

\section{Certificate in Work-based Learning}

This Level 5 short course on workplace instructional and educational techniques comprises three two-day intensive workshops and has been offered for a number of years to a range of industries. The principal challenges here show much conformity with those above, including:

- Learning environment: iterations of the programme have been run in settings ranging from university classrooms, conference centres, in-company and at military establishments, both indoors and outdoors according to the participants' arena of practice.

- Differentiation: cohorts may comprise individuals from the same organisation or company to those from diverse backgrounds - public services, private companies, the police, the military and small to medium enterprises.

- Entry level: Expectations, experience and motivations on entry are similarly varied with some participants eager to participate, others sceptical, even resentful having been 'volunteered' by their managers.

\section{Foundation Degrees}

Finally, the authors' extensive experience of facilitating WB foundation degree provision in the fields of education and health and social care illustrates similar themes and challenges as follows: 
- Perceived relevance or appropriateness of level: instances have arisen of participants being enrolled onto FD level programmes by line managers on the basis of relevance of content, regardless of participant holding existing qualifications at a higher academic level.

- Student self-concept: reactions ranging from passivity to active resistance often mask biographies of alienation and humiliation in relation to formal education and a consequent anxiety and reluctance to move out of personal comfort zones

- Workload balance: balancing the demands of work, family and study is a perennial issue which assumes a significance in fairly direct proportion to the individual's motivation.

- Confidence and credentials: some teaching staff are highly reluctant to operate outside their areas of expertise, considering work-based programmes and the collaborative facilitation arrangements as challenges to the purity of their disciplinary identities (see further above).

Many of these considerations are common to all forms of education and need not be restricted to WBL programmes so it follows that the solutions might well be relevant in a range of situations. We have found that there is no one solution, no one-size fits all, or golden bullet - yet in all contexts, the characterisation of WBL as a triadic learning endeavour has proved central to successful resolution of challenges, easing of tensions, and mitigation of learning obstacles. We addressed these challenges in the following ways:

- Diversification: Activity-based approaches such as scenario-planning, table-top exercises and drawing on the specialist expertise resident within the cohorts 
enabled those with less knowledge and experience to learn from those possessing them. The less motivated and the anxious can gain confidence through involvement with the group and gradually be prised out of their seclusion by sensitive facilitation.

- Technology: In additional to hard-copy handouts, we have found that establishing a rich Virtual Learning Environment (VLE) for each of the above programmes has enabled us to provide a wealth of resources, including information about the programme as well as access to those resources used on the programme and links to others which had not been used. For those conversant and confident with the technology, the VLE has proved beneficial, however those who did not access the VLE - despite repeated introductions to using it - the disadvantages remained.

- Teaching accommodation: Recognising the provision as 'academy aligned' rather than academy based, workshops and study days have been facilitated in venues more redolent of participants' workplaces than of the university lecture hall. Scheduling issues, particularly in relation to securing congenial venues calls for detailed advance planning but pays dividends in locating the learning in an environment where the triadic learning endeavour can flourish.

- Academic skills support: A 'Continuing Skills' Module (embedding core guidance on reflective practice, academic writing, strategies and conventions) has provided an invaluable safety net for those participants making use of it, particularly in the areas of managing priorities and workloads, whilst electronic submission of assignments and drafts as email attachments dissolves distances for those operating abroad. 
- Assessment regime: The use of an adapted version of the Patchwork Text assessment approach (Dalrymple \& Smith, 2008) has proved highly effective in providing rapid feedback to participants enabling them to monitor their progress and gain confidence in their abilities.

By all available measures including learner feedback, tutor observation, attainment data and progression statistics, such strategies have proved highly effective in harnessing work-based learners' capacities for reflection, promoting positive academic and professional outcomes, and realising a conception of WBL as a distinct learning process, a triadic learning endeavour.

\section{Conclusion}

The characterisation of WBL set out in this article aims to capture some of the unique dimensions of this increasing aspect of modern higher education practice whilst recognising the reality that the workplace has a number of constraints as a domain for learning. Increasingly, collaborative knowledge-creation and exchange are under scrutiny as budgets and staff-student ratios are reviewed in a context of diminishing and threatened resources. Likewise, the flexible delivery of knowledge must equate to the expectations of the actors. It is therefore important that these expectations are identified and addressed. Those controlling the workplace if not the participants, owe a duty to the workplace and thus the outcomes driven by the education must be seen as a reward or bonus to those enabling the participator to participate. However, this is very different for those who are single occupancy businesses where their educational demands are such that they are participating in a programme not only for personal gratification, but to gain for their business a 
competitive advantage, for example, by increasing the businesses' viability or to change the business to enable it to survive and thrive in challenging times.

The model of WBL set out in this article recognises that the practice is breaking new ground and modifying the ways in which learning and teaching in higher education are realised. Through the integration of a flexible relationship between participants, university tutors and industry specialists, new activities, delivery mechanisms and experiences are being conceived, developed and supported on an ever-increasing scale. This fosters a rich learning environment in which educational intentions are mediated and negotiated through an interactive pedagogy which has mutual benefits for all involved. Through reflection and experiential learning, work-based learning moves away from an academy-based model where theory invariably precedes practice and substitutes a triadic learning endeavour where all actors are equal participants.

This type of approach often flies in the face of the traditional educational experience and expectations, and opens all involved to a fast-moving, often temporary and very different educational process. This type of learning however can only be facilitated within a delivery model which is robust, yet flexible and the product of negotiation between those involved. In this sense, work-based learning is a supra system at the core of which is the mobilisation of the education/training confluence as a starting point for a more inclusive vision of higher education in the uncertain and fastchanging times in which modern workforces of all complexions must operate. 


\section{References}

Biggs, J. and Tang, C. (2011). Teaching for Quality Learning at University: What the Student Does, $4^{\text {th }}$ edn (Buckingham: Society for Research in Higher Education). Boud, D. \& Solomon, N. (2000). Working as the curriculum: pedagogical and identity implications. Working Paper 7. University of Technology, Sydney, NSW, Australia.

Boud, D. \& Solomon, N. (2001). Work-based Learning: A New Higher Education? (Buckingham: Society for Research into Higher Education) Centre for Outcomes-based Education (2006). Work-based learning: models and approaches. Milton Keynes. Open University.

Cowan, J. (1998). On becoming an innovative university teacher.

Buckingham. Society for Research into Higher Education \& Open University Press.

Crawshaw, M. (2008). How do adult learning theories relate to reflective practice? University of York.

Dalrymple, R. \& Smith, P. (2008). The Patchwork Text: enabling discursive writing and reflective practice on a foundation module in work-based learning. Innovations in Education and Teaching International. 45 (1). 47 - 54.

Eisner, E. (2000). From episteme to phronesis to artistry in study and improvement of teaching. Teaching \& Teacher Education. 10. $375-385$.

Eraut, M. (1994). Developing professional knowledge and competence. London. Falmer Press.

Eraut, M. (2000). Non-formal learning and tacit knowledge in professional work. British Journal of Educational Psychology. 70. 113 - 136. 
Eraut, M. (2009). How professionals learn through work.

http://learningtobeprofessional.pbworks.com/

Gamache, P. (2002). University students as creators of personal knowledge: an alternative epistemological view. Teaching in Higher Education. 7 (3). $277-294$.

Hoyle, E. (1975). The creativity of the school. In Harris, A. Lawn, M. \& Prescott, W. (eds) (1975). Curriculum innovation. London. Croom Helm \& The Open University Press.

Huff, A. (1999). Changes in organisational knowledge production. Academy of Management Review. 25 (2). 288 - 293.

Jaques, D. (2000). Learning in groups: a handbook for improving group work. London. Kogan Page.

Jarvis, P. (2001). (ed).The age of learning. London. Kogan Page.

Jarvis, P. Holford, J. \& Griffin, C. (2003). The theory and practice of learning. London. Kogan Page.

Knowles, M. (1978). The adult learner: a neglected species. Houston. Gulf. Lundeberg, M. (1987). Metacognitive aspects of reading comprehension: studying understanding in legal case analysis. Reading Research Quarterly. 22. $407-432$.

Marsick, V. (ed). (1987). Learning in the workplace. London. Croom Helm. Marsick, V. \& Watkins, K. (1990). Informal and incidental learning in the workplace. London. Routledge. Mezirow, J. (2000). Learning as transformation: critical perspectives on a theory in progress. San Francisco. Jossey-Bass.

Nixon, I. Smith, K. Stafford, R \& Camm, S. (2006). Work-based learning: 
illuminating the higher education landscape. York. Higher Education Academy.

McAlpine, I. Weston, C. Beauchamp, J. Wiseman, C \& Beauchamp, C. (1999).

Building a metacognitive model of reflection. Higher Education. 37. 105 131.

Mortensen, C., D (1972) Communication: The Study of Human

Communication. New York: McGraw-Hill Book Co.

Prosser, M. and Trigwell, K. (1999), Understanding Learning and Teaching:

The Experience in Higher Education (Buckingham: SRHE).

Quality Assurance Agency for Higher Education. (2007). (2nd ed). Code of practice for the assurance of academic quality and standards in higher education. Section 9. Work-based and placement learning.

QAA Scotland (2010), Making it work: a guidebook exploring work-based learning.

Raelin, J. (2008). Work-based Learning. San Francisco. Jossey-Bass.

Ramsden, P. (2003). Learning to Teach in Higher Education, 2nd edn (London: Routledge).

Revans, R.V. (1998). The ABC of action learning. London. Lemos \& Crane.

Robinson, K. (2010). Bring on the learning revolution. TED Conference.

http://www.ted.com/talk/sir ken robinson bring on the revolution

Rogers, A. (1986). Teaching adults. Buckingham. Open University/Society for Research into Higher Education.

Schramm

Schon, D. (1983). The reflective practitioner. San Francisco. Jossey-Bass.

Schon, D. (1987). Educating the reflective practitioner. San Francisco. 
Jossey-Bass.

Van der Elst (2009). Eyes wide open: embracing uncertainty through scenario. http://www.ftpress.com Accessed 30-10-2009.

Word count: 5126 